\title{
Influence of Doping Tb on the Mechanical Properties and Martensitic Transformation of Ni-Mn-Sn Magnetic Shape Memory Alloys
}

\author{
Xiaohua Tian ${ }^{1}$, Kun Zhang ${ }^{2}$, Changlong Tan ${ }^{1,2, *}$ and Erjun Guo ${ }^{2}$ \\ 1 School of Science, Harbin University of Science and Technology, Harbin 150080, China; \\ xiaohuatian@hrbust.edu.cn \\ 2 School of Materials Science and Engineering, Harbin University of Science and Technology, Harbin 150080, \\ China; kunzhang@hrbust.edu.cn (K.Z.); guoerjun@126.com (E.G.) \\ * Correspondence: changlongtan@hrbust.edu.cn; Tel.: +86-86-390-788
}

Received: 17 May 2018; Accepted: 5 June 2018; Published: 11 June 2018

\begin{abstract}
Brittleness and low working temperature are two key factors that restrict the application of Ni-Mn-Sn alloys. Element doping is an effective means to improve performance of materials. In present paper, martensitic transformation (MT) and mechanical properties of $\mathrm{Ni}_{48} \mathrm{Mn}_{39} \mathrm{Sn}_{13-x} \mathrm{~Tb}_{x}$ $(x=0,0.5,1,2$, and 5 at.\%) alloys are investigated. It is found that the Tb addition refines significantly the grains and causes the formation of a Tb-rich phase. All the samples undergo the martensitic transformation from parent phase to martensite. And the martensitic transformation characteristic temperatures increase remarkably from $-60.7^{\circ} \mathrm{C}$ for $x=0$ to $364.1^{\circ} \mathrm{C}$ for $x=5$. The appropriate amount of $\mathrm{Tb}$ addition in $\mathrm{Ni}_{48} \mathrm{Mn}_{39} \mathrm{Sn}_{13-x} \mathrm{~Tb}_{x}(x=0,0.5,1,2$, and 5 at.\%) alloys significantly enhances the compressive strength and improves the ductility, which can be ascribed to the grain refinement. The compressive stress of $571.8 \mathrm{MPa}$ and strain $22.0 \%$ are obtained in the $\mathrm{Ni}_{48} \mathrm{Mn}_{39} \mathrm{Sn}_{11} \mathrm{~Tb}_{2}$ alloy. Then the mechanical properties decrease with the further increased $\mathrm{Tb}$ content. Simultaneous improving of martensitic transformation temperature and mechanical properties in Ni-Mn-Sn magnetic alloy are achieved by $\mathrm{Tb}$ doping.
\end{abstract}

Keywords: Ni-Mn-Sn; ferromagnetic shape memory alloys; martensitic transformation; mechanical properties; $\mathrm{Tb}$ doping; rare earth element

\section{Introduction}

Compared to traditional shape memory alloys (SMAs), ferromagnetic shape memory alloys (FSMAs) can produce force and deformations by applying a magnetic field. Owing to the strong coupling between structure and magnetism, the ferromagnetic shape memory alloys (FSMAs) have attracted considerable attention [1-10]. As a typical magneto-structurally coupled ferromagnetic shape memory alloy (FSMAs), Ni-Mn-Sn alloys undergo a magnetic-field-induced reverse martensitic transformation from antiferromagnetic martensite to ferromagnetic austenite. On this basis, Ni-Mn-Sn FSMAs exhibit rich multifunctional properties, such as the magnetic field induced shape memory effect, giant magnetoresistance [11,12], magnetocaloric effect (MCE) [13,14], and the elastocaloric effect (eCE) [15].

The MCE is a magneto-thermodynamic phenomenon in which a temperature change of a suitable material is caused by exposing the material to a changing magnetic field [13,16-22]. Magnetic refrigeration is a new cooling technology utilizing the MCE. In comparison, based on the elastocaloric effect, similar caloric effects are demonstrated by application of mechanical stress. And these materials with the elastocaloric effect have recently attracted tremendous attention due to the large available latent heat and large adiabatic temperature changes. Either based on the MCE or eCE, the materials 
all show the largest potential to replace the traditional vapor-compression technologies due to the zero-production of ozone-depleting or greenhouse gases. Quite recently, a large temperature change of $4 \mathrm{~K}$ was found during compressing the sample of $\mathrm{Ni}_{45} \mathrm{Mn}_{44} \mathrm{Sn}_{11}$ with a small transformation strain of $1.3 \%$ at $291.5 \mathrm{~K}$ [23]. All of these indicate that, as a typical multiferroic material with a large magnetoelastic effect or elastocaloric effect, Ni-Mn-Sn FSMAs are regarded as having potential for environmentally-friendly solid-state refrigeration materials.

Because the alloys with poor mechanical properties normally crack under repeated stress cycling, the cooling life is reduced. The real utilization of magnetocaloric materials and elastocaloric materials both demand good mechanical properties. Unfortunately, now, the main drawback of existing $\mathrm{Ni}-\mathrm{Mn}-\mathrm{Sn}$ alloys is its nature of high brittleness and poor mechanical properties. Therefore, it is urgent to solve the brittleness problem. Additionally, due to the coupling of the martensitic transformation and ferromagnetic transition, the existing Ni-Mn-Sn FSMAs show a lower working temperature. Now, only very few studies have been performed in order to increase the working temperature of these FSMAs, which is also one of the principal requirements for the practical application.

Many efforts have been put forward on the improvement of the mechanical properties of other Ni-Mn based alloys, including the element substitution and the secondary phase inclusion [24-28]. As previously reported, the addition of rare earth elements such as $\mathrm{Sm}, \mathrm{Tb}, \mathrm{Dy}, \mathrm{Nd}$, and $\mathrm{Y}$, enhances the ductility of Ni-Mn-Ga alloys [29]. Moreover, we all know that the largest MCEs to date have been observed in $\mathrm{Gd}_{5} \mathrm{Si}_{2} \mathrm{Ge}_{2}$, which are currently based on rare earth materials [30]. So, rare earth element addition may play a positive role in solid-state refrigeration. Meanwhile, some researchers have reported that rare earth element addition could improve the martensitic transformation temperature. Therefore, it can be anticipated that doping a suitable rare earth element into Ni-Mn-Sn FSMAs may simultaneously tune the mechanical properties and martensitic transformation temperature. There is still a lack of knowledge and information about the rare earth element Tb addition in Ni-Mn-Sn FSMAs. In this paper, we anticipate that $\mathrm{Tb}$ addition in Ni-Mn-Sn alloys will have an amazing effect on the mechanical properties and martensitic transformation behavior. Finally, the results show that the martensitic transformation characteristic temperatures increase remarkably with the increase in $\mathrm{Tb}$ content. The compressive stress increases from 74.3 MPa to 571.8 MPa and the compressive strain increase form $9.2 \%$ to $22.0 \%$ with increasing $\mathrm{Tb}$ content from 0 at. $\%$ to 2 at. $\%$.

\section{Materials and Methods}

The nominal composition of the alloy $\mathrm{Ni}_{48} \mathrm{Mn}_{39} \mathrm{Sn}_{13-x} \mathrm{~Tb}_{x}(x=0,0.5,1,2$, and 5 at.\%) were prepared with high purity elements nickel, manganese, stannum, and Terbium, with a purity levels of $99.99 \%, 99.95 \%, 99.99 \%$, and $99.9 \%$, respectively, by melting six times in a non-consumed vacuum arc furnace under argon atmosphere. In this paper, the nominal composition of the $\mathrm{Ni}_{48} \mathrm{Mn}_{39} \mathrm{Sn}_{13-x} \mathrm{~Tb} x$ $(x=0,0.5,1,2$, and 5$)$ alloys are marked as $\mathrm{Tb} 0, \mathrm{~Tb} 0.5, \mathrm{~Tb} 1, \mathrm{~Tb} 2$, and $\mathrm{Tb} 5$. The six re-melts were to ensure a uniform alloy composition. The cast samples were sealed in quartz tubes under a pressure of $10^{-3} \mathrm{~Pa}$, then annealed at $1123 \mathrm{~K}$ for $24 \mathrm{~h}$, and then quenched in ice water for homogeneity.

The microstructure of the alloys at room temperature was examined using an Olympus metallographic microscope and scanning electron microscopy (SEM, TESCAN VEGA3-SBH) equipped with energy dispersive X-ray spectroscopy (EDS). The samples were etched using $4 \%$ picric acid. The crystal structure at room temperature was determined by X-ray diffraction (XRD, Rigaku $\mathrm{D} / \mathrm{max}-\mathrm{Rb}$ with $\mathrm{Cu} \mathrm{K} \alpha$ radiation). The transformation temperatures were determined by differential scanning calorimetry (DSC) measurements with the TA-2920. The heating and cooling rates were $20 \mathrm{~K} / \mathrm{min}$. The compression tests were performed at room temperature on an Instron 5569 testing system at a crosshead displacement speed of $0.1 \mathrm{~mm} / \mathrm{min}$, and the size of the sample was $3 \mathrm{~mm} \times 3 \mathrm{~mm} \times 5 \mathrm{~mm}$. Fractography was observed by SEM to study the dominant fracture behavior in this alloy system. 


\section{Results and Discussion}

\subsection{Structure}

Figure 1 shows the optical micrographs of solution-treated $\mathrm{Ni}_{48} \mathrm{Mn}_{39} \mathrm{Sn}_{13-x} \mathrm{~Tb}_{x}(x=0,0.5,1,2$, and 5) alloys at room temperature. Evidently, it can be seen that the grain size of $\mathrm{Ni}_{48} \mathrm{Mn}_{39} \mathrm{Sn}_{13}$ alloy decreased with an increase in $\mathrm{Tb}$ content. From Figure 1a we can find that the microstructure of $\mathrm{Ni}_{48} \mathrm{Mn}_{39} \mathrm{Sn}_{13}$ alloy without $\mathrm{Tb}$ addition consisted of coarser equiaxed grains, and the grain size was approximately $160 \mu \mathrm{m}$. The grain size of the $\mathrm{Ni}_{48} \mathrm{Mn}_{39} \mathrm{Sn}_{13-x} \mathrm{~Tb}_{x}(x=0,0.5,1,2$, and 5$)$ alloys was reduced significantly by $\mathrm{Tb}$ addition. In the optical micrographs, the grains were marked by white dashed lines approximately. When the content of $\mathrm{Tb}$ addition was 2 at.\%, the average grain size was reduced to $10 \mu \mathrm{m}$. These results were consistent with those obtained in the previous investigations when adding rare earth elements into the single martensite Ni-Mn-Ga alloys [31]. In addition, with the addition of $\mathrm{Tb}$, the second phase appeared and distributed sporadically. With the further addition of $\mathrm{Tb}$, the second phase increased and distributed along the grain boundaries. A network-like distribution and local enrichment of the second phase were also observed in the $\mathrm{Ni}_{48} \mathrm{Mn}_{39} \mathrm{Sn}_{11} \mathrm{~Tb}_{2}$ alloy, as shown in Figure 1d. As to the $\mathrm{Ni}_{48} \mathrm{Mn}_{39} \mathrm{Sn}_{8} \mathrm{~Tb}_{5}$ alloy, when the content of Tb further increased to 5 at.\%, the optical micrograph showed the significantly different microstructure with other alloys. With excessive $\mathrm{Tb}$ addition, the amount of the second phase increased abundantly, and more and more $\mathrm{Tb}$-rich phase enriched. And the distribution of the second phase was not uniform. Such that the matrix was segregated into many small islands. In this case, the grain boundaries were different and blurry, just as shown in Figure 1e.
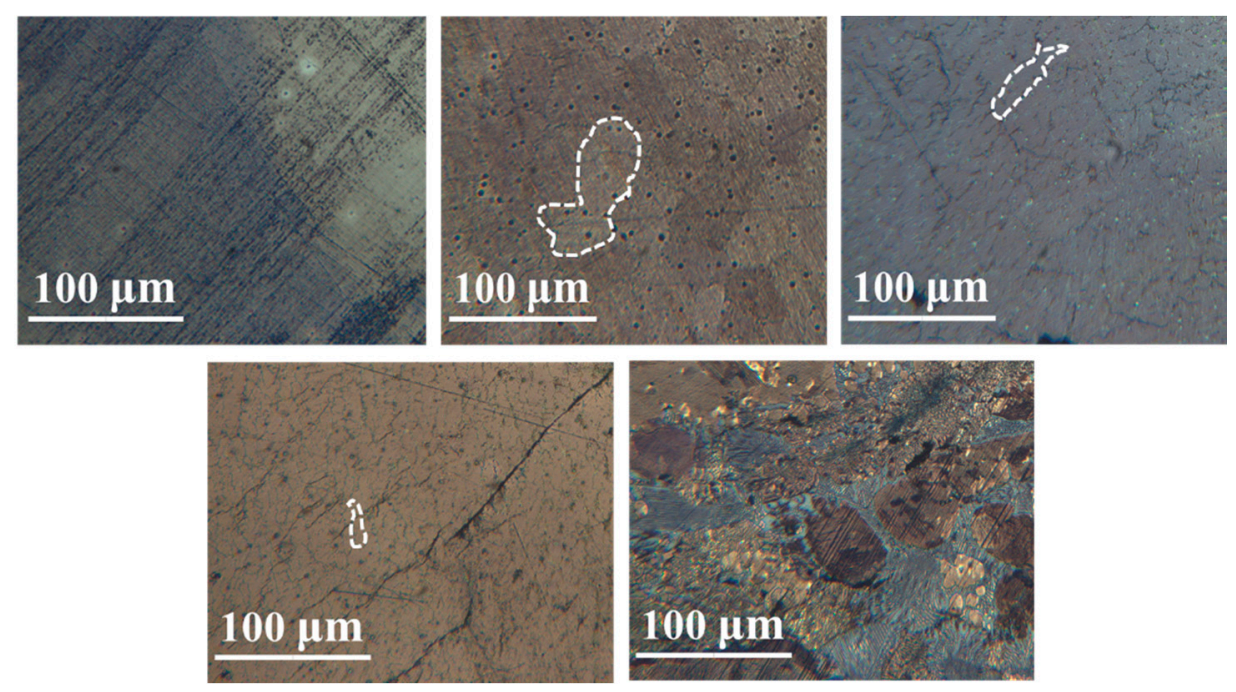

Figure 1. Optical micrographs of solution treated Ni48Mn39Sn13-xTbx alloys $(\mathbf{a}) \mathrm{x}=0$; (b) $\mathrm{x}=0.5$; (c) $\mathrm{x}=1 ;(\mathbf{d}) \mathrm{x}=2 ;(\mathbf{e}) \mathrm{x}=5$.

In order to ascertain the possibility of the second phase segregation in the present samples, detailed microstructural studies have been carried out by using SEM. Figure 2 shows the backscattered electron images of $\mathrm{Ni}_{48} \mathrm{Mn}_{39} \mathrm{Sn}_{13-x} \mathrm{~Tb}_{x}(x=0,0.5,1,2$, and 5) alloys. It can be seen that a segregation occurred at the grain boundaries. This was consistent with the results of the optical micrographs. Different as compared to the alloy without $\mathrm{Tb}$ addition shown in Figure $2 \mathrm{a}$, the other micrographs show a dual-phase microstructure with the black matrix and the white second phase. Apparently, rare earth element $\mathrm{Tb}$ addition changed the microstructure of $\mathrm{Ni}_{48} \mathrm{Mn}_{39} \mathrm{Sn}_{13}$ alloy. $\mathrm{Ni}_{48} \mathrm{Mn}_{39} \mathrm{Sn}_{13}$ alloy showed the structure with single phase. The white second phase was observed in all of the samples with $\mathrm{Tb}$ addition. As the $\mathrm{Tb}$ content increased gradually, the size, quantity and distribution of the second phase were different. When the content of $\mathrm{Tb}$ was 0.5 at. $\%$, some small granular second phases 
distributed sporadically in the matrix, as indicated by the arrows shown in the Figure $2 \mathrm{~b}$. When the content of $\mathrm{Tb}$ was $1 \mathrm{at} . \%$, the second phase increases and the volume fraction increased gradually, then tended to distribute along the grain boundaries, as shown by the arrows in Figure 2c. When the content of $\mathrm{Tb}$ increased to 2 at.\%, the second phases along the grain boundaries began to connect to each other, then distributed like network and enriched locally. It is worth noting that the structure was completely different with the other alloys with $\mathrm{Tb}$ addition, as shown in the magnification of region in Figure 2e. From the magnification of region, the $\mathrm{Ni}_{48} \mathrm{Mn}_{39} \mathrm{Sn}_{8} \mathrm{~Tb}_{5}$ alloy was consistent with the black matrix and second phase, which showed a eutectic structure like "chrysanthemum". The second phase were lamellar in the grains, whereas those along the grain boundaries were irregular and had a larger size than those in the grains.

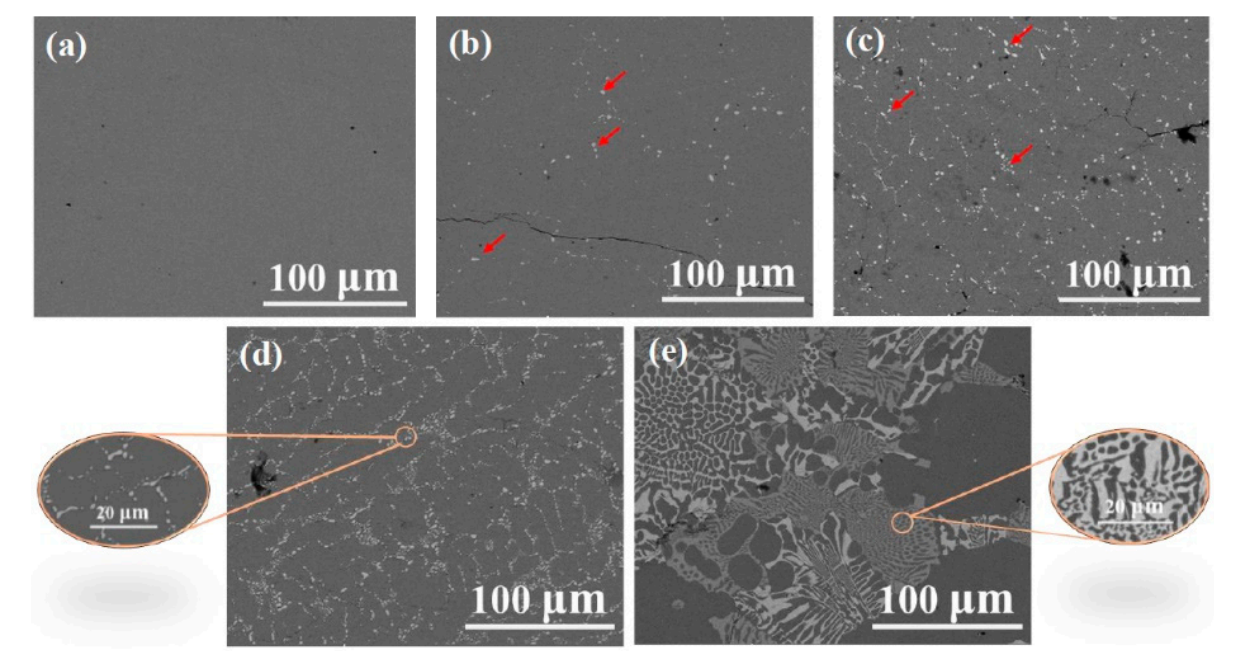

Figure 2. Backscattered electron images of $\mathrm{Ni}_{48} \mathrm{Mn}_{39} \mathrm{Sn}_{13-\mathrm{x}} \mathrm{Tb}_{\mathrm{x}}$ alloys $(\mathbf{a}) \mathrm{x}=0$; (b) $\mathrm{x}=0.5 ;(\mathbf{c}) \mathrm{x}=1$; (d) $\mathrm{x}=2 ;(\mathbf{e}) \mathrm{x}=5$.

In order to further investigate the detailed composition of the second phase, the composition of matrix and second phase of the $\mathrm{Ni}_{48} \mathrm{Mn}_{39} \mathrm{Sn}_{13-x} \mathrm{~Tb}_{x}(x=0,0.5,1,2$, and 5) alloys are listed in Table 1 . Each of these data is the average of five collection points. From the Table 1, it is found that the second phase (white areas) consisted of the elements $\mathrm{Ni}, \mathrm{Mn}, \mathrm{Sn}$, and $\mathrm{Tb}$. Compared to the composition of the matrix, the $\mathrm{Tb}$ content and Sn content of the second phase was higher, and the Ni content decreased slightly, while the Mn content was lower. Moreover, it was found that Tb addition had an obvious effect on the composition of the matrix. The nominal composition of these alloys was $\mathrm{Ni}_{48} \mathrm{Mn}_{39} \mathrm{Sn}_{13-x} \mathrm{~Tb}_{x}(x=0,0.5,1,2$, and 5), namely the content of $\mathrm{Ni}$ and $\mathrm{Mn}$ remained unchanged. While the EDS results show that the Mn content of matrix increased with the Tb addition, which was up to 43.78 at.\% in the $\mathrm{Ni}_{48} \mathrm{Mn}_{39} \mathrm{Sn}_{8} \mathrm{~Tb}_{5}$ alloy from 39.12 at.\% in $\mathrm{Ni}_{48} \mathrm{Mn}_{39} \mathrm{Sn}_{12.5} \mathrm{~Tb}_{0.5}$ alloy. Because the martensitic transformation temperature is sensitive to the composition of the alloy, this change will have a significant effect on the martensitic transformation behavior and mechanical properties of these alloys. It will be discussed in the next parts. Compared with the Tb content of the matrix and the second phase, the solubility of rare earth element $\mathrm{Tb}$ in the matrix was less than $0.2 \%$, while the solubility of rare earth element $\mathrm{Tb}$ in the second phase was very high in the range from $11.31 \mathrm{at} . \%$ to 14.18 at.\%. Through these results, we recognize that the second phase was Tb-rich phase. As we all know, the atom sizes of Ni, Mn and Sn are $0.124 \mathrm{~nm}, 0.129 \mathrm{~nm}$ and $0.158 \mathrm{~nm}$, respectively, while the atom size of $\mathrm{Tb}$ is $0.178 \mathrm{~nm}$. We recognize that the low solubility of rare earth element $\mathrm{Tb}$ in the matrix may be attributed to the large atom size of $\mathrm{Tb}$. 
Table 1. The EDS results of $\mathrm{Ni}_{48} \mathrm{Mn}_{39} \mathrm{Sn}_{13-x} \mathrm{~Tb}_{x}$ (at.\%).

\begin{tabular}{cccccc}
\hline Phase & $\mathbf{x}$ & $\mathbf{N i}$ & $\mathbf{M n}$ & $\mathbf{S n}$ & $\mathbf{T b}$ \\
\hline \multirow{4}{*}{ Matrix } & 0 & 47.92 & 38.78 & 13.30 & 0.00 \\
& 0.5 & 48.32 & 39.12 & 12.39 & 0.17 \\
& 1 & 48.25 & 40.82 & 10.75 & 0.18 \\
& 2 & 48.78 & 41.47 & 9.58 & 0.17 \\
Second phase & 5 & 49.87 & 43.68 & 6.26 & 0.19 \\
\hline & 0.5 & 44.78 & 24.03 & 20.88 & 10.31 \\
& 1 & 41.85 & 23.70 & 23.27 & 11.18 \\
& 2 & 42.12 & 22.73 & 22.33 & 12.82 \\
& 5 & 41.54 & 21.82 & 22.18 & 14.46 \\
\hline
\end{tabular}

To further confirm the structure of the alloys and the second phase, $\mathrm{X}$-ray diffraction patterns of $\mathrm{Ni}_{48} \mathrm{Mn}_{39} \mathrm{Sn}_{13-x} \mathrm{~Tb}_{x}(x=0,0.5,1,2$, and 5$)$ alloys at room temperature are shown in Figure 3. Compared with the reflection of Ni-Mn-Sn alloys reported by Krenke et al., the main reflection peaks corresponding to the cubic austenite were marked by the red squares [32]. The main reflection peaks corresponding to the martensite were marked by the blue circles, and some extra reflection peaks corresponding to the $\gamma$-phase are marked by the pink triangles. From the XRD patterns, the typical diffraction peaks from austenite can be clearly seen in the $\mathrm{Tb} 0$ and $\mathrm{Tb} 0.5$ samples. They show the single austenite crystal structure, which can be indexed by the $L 2_{1}$ structure. Because the martensitic transformation temperature was below the room temperature, these two samples all showed the austenite crystal structure at room temperature. As to the details of the martensitic transformation temperature, we will discuss them in the next parts later. A small difference with the Tb0 sample, a weak $\gamma$-phase peak appeared. With the further increase of $\mathrm{Tb}$ content, when the content of $\mathrm{Tb}$ was 1 at.\%, the $\mathrm{Ni}_{48} \mathrm{Mn}_{39} \mathrm{Sn}_{12} \mathrm{~Tb}_{1}$ alloy showed a more complicated case, exhibiting a mixed structure of the cubic austenite phase, orthorhombic martensite phase, and the $\gamma$-phase. The $\mathrm{Ni}_{48} \mathrm{Mn}_{39} \mathrm{Sn}_{11} \mathrm{~Tb}_{2}$ alloy presented a two-phase structure, with the $\gamma$-phase and the orthorhombic martensite phase. When the $\mathrm{Tb}$ content increased to 5 at. $\%$, the peaks of martensite phase became weak, while the peaks of the $\gamma$-phase became stronger. The SEM observation mentioned above indicates that the amount of Tb-rich phase in the $\mathrm{Ni}_{48} \mathrm{Mn}_{39} \mathrm{Sn}_{8} \mathrm{~Tb}_{5}$ alloy was greater than that in the other alloys. Thus, it is speculated that these unknown peaks may be from the Tb-rich phase.

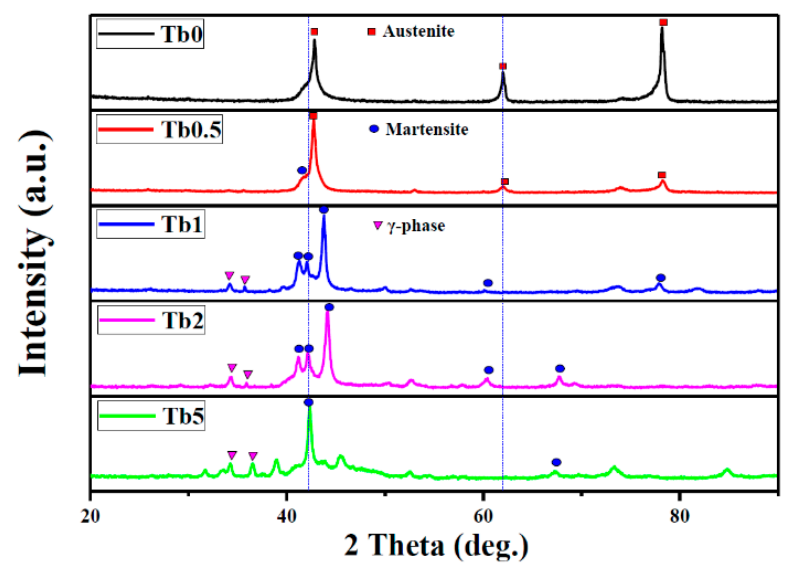

Figure 3. X-ray diffraction patterns of $\mathrm{Ni}_{48} \mathrm{Mn}_{39} \mathrm{Sn}_{13-\mathrm{x}} \mathrm{Tb}_{\mathrm{x}}$ alloys.

\subsection{Martensitic Transformation}

Figure 4 shows the DSC curves of the $\mathrm{Ni}_{48} \mathrm{Mn}_{39} \mathrm{Sn}_{13-x} \mathrm{~Tb}_{x}(x=0,0.5,1,2$, and 5) alloys. The martensitic transformation was detected over the whole composition range, as evidenced by the endothermic and exothermic peaks observed upon the heating and cooling cycles respectively. 
Table 2 lists the martensitic transformation starting and finishing temperatures $\left(M_{\mathrm{s}}, M_{\mathrm{f}}\right)$, and the austenite starting and finishing temperature $\left(A_{\mathrm{s}}, A_{\mathrm{f}}\right)$. The transformation temperatures were taken as the intersection point of two baselines, as shown in Figure 4. The typical DSC curves in the $\mathrm{Ni}_{48} \mathrm{Mn}_{39} \mathrm{Sn}_{13}$ alloy and $\mathrm{Ni}_{48} \mathrm{Mn}_{39} \mathrm{Sn}_{12.5} \mathrm{~Tb}_{0.5}$ alloy exhibited the exothermic peak on cooling and the endothermic peak during heating, corresponding to the martensitic and reverse transformations, respectively. It is worth noting that a pair of step-like peaks appeared at the same temperature, as shown in the black arrows. We recognize these temperatures were the Curie temperatures of the alloys. We find that small amount of Tb addition did not change the curie temperature. This result was consistent with the previous research [32]. In contrast, the peaks corresponding to the Curie temperature could not be detected when the $\mathrm{Tb}$ content was above 1 at.\%. It is mainly due to the reverse martensitic transformation temperature being higher than the room temperature. What is more interesting, except for the main peaks, we found that another peak appeared behind them, as indicated by the red circles in the Figure 4. Combined with the analysis mentioned above, with excessive $\mathrm{Tb}$ addition, the amount of the second phase increased abundantly, and more and more of the Tb-rich phase was enriched. These unknown peaks may indicate the phase-transition temperatures of the Tb-rich phase. In the present paper, we are not going to explain this in further detail, and we will investigate this phenomenon in future research. In order to observe the changing tendency of the characteristic temperatures, the composition as a function of $M_{\mathrm{s}}, M_{\mathrm{f}}, A_{\mathrm{s}}$ and $A_{\mathrm{f}}$ are plotted in Figure 5 . Evidently, it was found that the martensitic transformation characteristic temperatures increased almost linearly with increasing $\mathrm{Tb}$ content. The martensitic transformation start temperature, $M_{\mathrm{s}}$, increased from $-60.7^{\circ} \mathrm{C}$ for $x=0$ to $364.1^{\circ} \mathrm{C}$ for $x=5$. We all know that the martensitic transformation temperature $M_{\mathrm{S}}$ is sensitive to the composition of alloys. Therefore, the main reason that $\mathrm{Tb}$ addition changed the $M_{\mathrm{s}}$ was the change of composition. As above analysis in Table 1, the solubility of Tb in the matrix was found to be very low. The insoluble Tb element segregated mainly at the grain boundaries and formed the Tb-rich phase. The EDS results also showed that the composition of the matrix was changed by the existence of the Tb-rich phase. With the increasing of $\mathrm{Tb}$ content, the content of $\mathrm{Mn}$ in the matrix increased gradually from 38.58 at. $\%$ for $x=0$ to 43.78 at. $\%$ for $x=5$. Whereas the decrease of Sn content occurred due to the substitution of $\mathrm{Tb}$ for $\mathrm{Sn}$. At the same time, the content of Ni was almost kept constant. Consequently, the ratio of $\mathrm{Mn}$ and $\mathrm{Sn}$ increased as the content of $\mathrm{Ni}$ was approximately unchanged, which account for the increase of martensitic transformation temperature. This was accordance with the results obtained by Jiang et al. [33]. To verify this, first principles calculations are needed. However, due to the low solubility of $\mathrm{Tb}$ element, the $\mathrm{Tb}$ ions cannot enter into the lattice of the matrix. It is unreasonable to simulate the $\mathrm{Sn}$ atoms being replaced by $\mathrm{Tb}$ atoms. Nevertheless, the composition of the matrix was changed, based on adjusting the ratio of the atoms in each unit cell, we may reveal the influence of martensitic transformation behavior. This work will be completed in our future research.

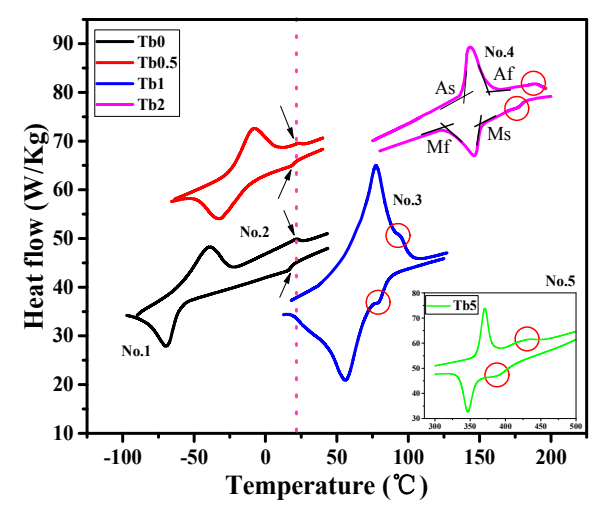

Figure 4. DSC curves of the $\mathrm{Ni}_{48} \mathrm{Mn}_{39} \mathrm{Sn}_{13-x} \mathrm{~Tb}_{x}$ alloys. 
Table 2. The characteristic temperatures of $\mathrm{Ni}_{48} \mathrm{Mn}_{39} \mathrm{Sn}_{13-x} \mathrm{~Tb}_{x}$ alloys $(x=0,0.5,1,2,5$ at. \%) denoted as $M_{\mathrm{s}}, M_{\mathrm{f}}, A_{\mathrm{s}}$ and $A_{\mathrm{f}}$, respectively.

\begin{tabular}{ccccc}
\hline Composition & $\boldsymbol{M}_{\mathbf{s}}\left({ }^{\circ} \mathrm{C}\right)$ & $\boldsymbol{M}_{\mathbf{f}}\left({ }^{\circ} \mathrm{C}\right)$ & $\boldsymbol{A}_{\mathbf{s}}\left({ }^{\circ} \mathrm{C}\right)$ & $\boldsymbol{A}_{\mathbf{f}}\left({ }^{\circ} \mathrm{C}\right)$ \\
\hline $\mathrm{Ni}_{48} \mathrm{Mn}_{39} \mathrm{Sn}_{13}$ & -60.7 & -83.7 & -61.2 & -25.4 \\
$\mathrm{Ni}_{48} \mathrm{Mn}_{39} \mathrm{Sn}_{12.5} \mathrm{~Tb}_{0.5}$ & -16.8 & -49.8 & -24.5 & 6.7 \\
$\mathrm{Ni}_{48} \mathrm{Mn}_{39} \mathrm{Sn}_{12} \mathrm{~Tb}_{1}$ & 77.4 & 36 & 49.8 & 42.0 \\
$\mathrm{Ni}_{48} \mathrm{Mn}_{39} \mathrm{Sn}_{11} \mathrm{~Tb}_{2}$ & 149.7 & 125.8 & 138.9 & 169.7 \\
$\mathrm{Ni}_{48} \mathrm{Mn}_{39} \mathrm{Sn}_{8} \mathrm{~Tb}_{5}$ & 364.1 & 337.9 & 361.7 & 382.3 \\
\hline
\end{tabular}

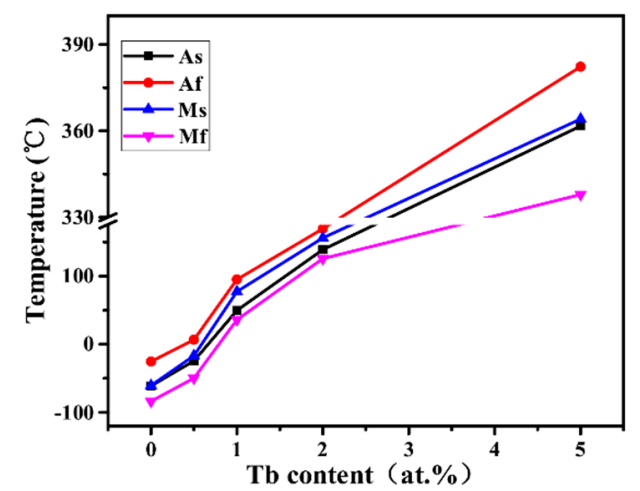

Figure 5. The effect of $\mathrm{Tb}$ content on the phase transformation temperatures of $\mathrm{Ni}_{48} \mathrm{Mn}_{39} \mathrm{Sn}_{13-x} \mathrm{~Tb}_{x}$ $(x=0,0.5,1,2,5)$ alloys.

\subsection{Mechanical Properties}

Good mechanical properties play an important role in the practical application of Ni-Mn-Sn FSMAs. In order to obtain the strength and ductility behavior of the $\mathrm{Ni}_{48} \mathrm{Mn}_{39} \mathrm{Sn}_{13-x} \mathrm{~Tb}_{x}(x=0,0.5$, 1,2 , and 5) alloys, the compressive mechanical properties were tested for the alloys. The alloys were loaded at room temperature until failure in compression. Figure 6 shows the representative compressive stress-strain curves. The effect of rare earth element $\mathrm{Tb}$ content on the compressive strength and the compressive strain of $\mathrm{Ni}_{48} \mathrm{Mn}_{39} \mathrm{Sn}_{13-x} \mathrm{~Tb}_{x}(x=0,0.5,1,2$, and 5) alloys are plotted in Figure 7. As can be seen, without $\mathrm{Tb}$ addition, the $\mathrm{Ni}_{48} \mathrm{Mn}_{39} \mathrm{Sn}_{13}$ alloy had the worse failure stress and strain among the tested alloys. The detected compressive stress and strain were $74.3 \mathrm{MPa}$ and $\sim 9.2 \%$ separately. In Figure 7, it can be seen that both the compressive stress and strain had a strong dependence upon the $\mathrm{Tb}$ content. In addition to the $\mathrm{Ni}_{48} \mathrm{Mn}_{39} \mathrm{Sn}_{8} \mathrm{~Tb}_{5}$ alloy, the compressive stress and strain of all the other samples increased nearly linearly as $\mathrm{Tb}$ content increased. When $\mathrm{Tb}$ content was increased to 2 at. $\%$, the compressive strain was evidently increased to $22.0 \%$, and the compressive stress was significantly improved to $571.8 \mathrm{MPa}$. As to the $\mathrm{Ni}_{48} \mathrm{Mn}_{39} \mathrm{Sn}_{8} \mathrm{~Tb}_{5}$ alloy, when the content of $\mathrm{Tb}$ further increased to $5 \mathrm{at} \%$, the compressive stress and strain decreased slightly compared with that of $\mathrm{Ni}_{48} \mathrm{Mn}_{39} \mathrm{Sn}_{11} \mathrm{~Tb}_{2}$ alloy. But the mechanical property of $\mathrm{Ni}_{48} \mathrm{Mn}_{39} \mathrm{Sn}_{11} \mathrm{~Tb}_{2}$ alloy was still much better than that of alloy without $\mathrm{Tb}$ addition. The best comprehensive mechanical property was effectively hindering the movement of dislocations and the propagation of cracks, which was the reason for the enhancement of the compressive strength and strain. As mentioned before, the grain size of the $\mathrm{Ni}_{48} \mathrm{Mn}_{39} \mathrm{Sn}_{13-x} \mathrm{~Tb}_{x}(x=0,0.5,1,2$, and 5) alloys decreased with increases of Tb content. It appears that the refinement of grain size had a beneficial effect on the strength and ductility of the alloys. Moreover, the size and distribution of Tb-rich phase played an important role in the improvement of mechanical properties. With increasing $\mathrm{Tb}$ addition, the Tb-rich phase grew and tended to distribute along the grain boundaries. The existence of $\mathrm{Tb}$-rich phase at the grain boundaries effectively hindered the movement of dislocation and the propagation of cracks, which was also the key to improving the mechanical properties of alloys. Some researchers have found that a large amount of $\operatorname{Re}(\mathrm{Ni}, \mathrm{Mn})_{4} \mathrm{Ga}$ phases can improve the compressive ductility and strength of single phase martensitic $\mathrm{Ni}_{50} \mathrm{Mn}_{29} \mathrm{Ga}_{21}$ 
alloys $[24,26]$. However, here we found that a large number of Tb-rich phases played a negative role in the ductility improvement in two-phase Ni-Mn-Sn-Tb alloys. It was confirmed that the Re-rich phase is a hard-brittle phase, which might fracture earlier than the matrix in the deformation process and form a large number of defects, leading to a drop in mechanical performance [34]. This might be the reason why the alloys showed the drop in mechanical performance when the Tb addition was 5 at. $\%$. All these above clearly indicated that the proper amount of $\mathrm{Tb}$ addition significantly improved the compressive strength and enhanced the ductility of the alloys.

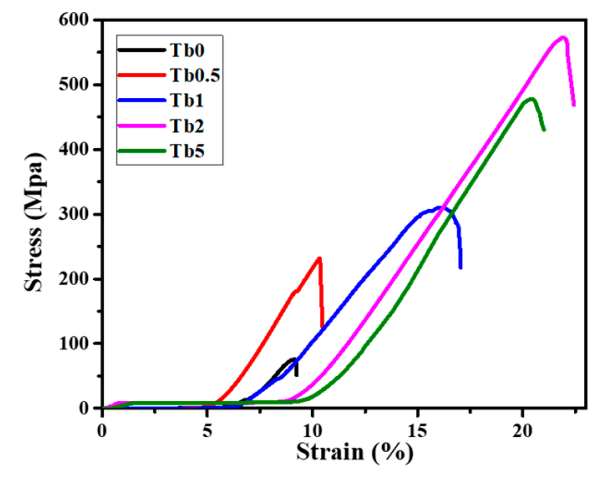

Figure 6. The compressive stress-strain curves of $\mathrm{Ni}_{48} \mathrm{Mn}_{39} \mathrm{Sn}_{13-x} \mathrm{~Tb}_{x}$ alloys.
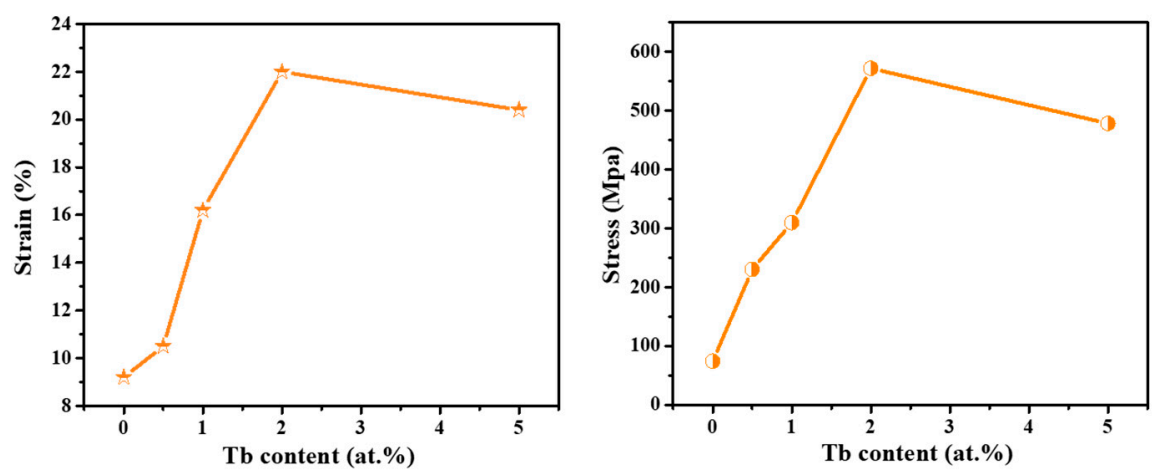

Figure 7. The effect of $\mathrm{Tb}$ content on the compressive strength and the compressive strain of $\mathrm{Ni}_{48} \mathrm{Mn}_{39} \mathrm{Sn}_{13-x} \mathrm{~Tb}_{x}$ alloys.

In order to further clarify the fracture mechanism, the fracture morphologies of $\mathrm{Ni}_{48} \mathrm{Mn}_{39} \mathrm{Sn}_{13-x} \mathrm{~Tb}_{x}(x=0,0.5,1,2$, and 5) alloys after compressing were observed, as shown in Figure 8. With the addition of $\mathrm{Tb}$, the compactness of alloys was increased, which can be seen intuitively in Figure 8a-d. It was consistent with the above that $\mathrm{Tb}$ can refine the grain size. Figure 8a shows the fractograph of the alloy without $\mathrm{Tb}$ addition. The fracture surface was smooth and the edge was clear. It shows the typical brittle fracture along the grain boundaries. Due to the binding strength of the coarse grains were weak, the fracture originated from the grain boundary separation. The coarse grains and the intergranular fracture show the poor mechanical properties of the $\mathrm{Ni}_{48} \mathrm{Mn}_{39} \mathrm{Sn}_{13}$ alloy, which was consistent with the results of the compressive stress-strain curves shown in Figure 6. For the $\mathrm{Ni}_{48} \mathrm{Mn}_{39} \mathrm{Sn}_{12.5} \mathrm{~Tb}_{0.5}$ alloy, transgranular cracks with tearing edges were observed as shown in the Figure $8 \mathrm{~b}$. It shows characteristics of ductile transgranular fracture and plastic deformation occurred before fracturing. With the further addition of $\mathrm{Tb}$, lots of dimples with tearing ridges appeared, and the alloys exhibited cleavage fracture, as shown in the Figure 8c,d. The type of fracture changeed from intergranular fracture to transgranular fracture. Different to the alloy without $\mathrm{Tb}$ addition, in $\mathrm{Ni}_{48} \mathrm{Mn}_{39} \mathrm{Sn}_{11} \mathrm{~Tb}_{2}$ alloy, the fracture occurred within the grain, then the fracture grew past the grain boundary. This indicates that $\mathrm{Tb}$ addition strengthened the grain boundary. From the before mentioned microstructures of $\mathrm{Ni}_{48} \mathrm{Mn}_{39} \mathrm{Sn}_{13-x} \mathrm{~Tb}_{x}(x=0,0.5,1,2$, and 5) alloys, it was shown that 
the grain size of $\mathrm{Ni}_{48} \mathrm{Mn}_{39} \mathrm{Sn}_{11} \mathrm{~Tb}_{2}$ alloy was significantly reduced. More energy was needed when the fracture grew, because the crack propagation had to change direction several times to move through the grain boundary. This led directly to the difficulty in the formation and propagation of the fracture. Therefore, we recognize that grain refinement was the main reason for the alloy's plasticity enhancement. In addition, the alloy contained some Tb-rich phase, which distributed along the grain boundaries discontinuously. When plastic deformation occurred, the cracks grown along the grain boundaries were retarded by the Tb-rich phase. These two reasons mentioned above, improved the mechanical properties of the $\mathrm{Ni}_{48} \mathrm{Mn}_{39} \mathrm{Sn}_{11} \mathrm{~Tb}_{2}$ alloy. As to the $\mathrm{Ni}_{48} \mathrm{Mn}_{39} \mathrm{Sn}_{8} \mathrm{~Tb}_{5}$ alloy, it showed a distinct difference with others, as shown in Figure 8e. It can be seen that the second phases with large size were torn off from the matrix, as shown with arrows in Figure 8e. For higher volumes of Tb-rich phase, the hard-brittle phase distributed like network along the grain boundaries and enriched locally. This led to the continuity of the matrix being destroyed. With excessive Tb addition, more and more Tb-rich phases were enriched. When plastic deformation occurred, the cracks generated preferentially and propagated rapidly along the phase boundary of the matrix and Tb-rich phase. It resulted in the increase in the brittleness.

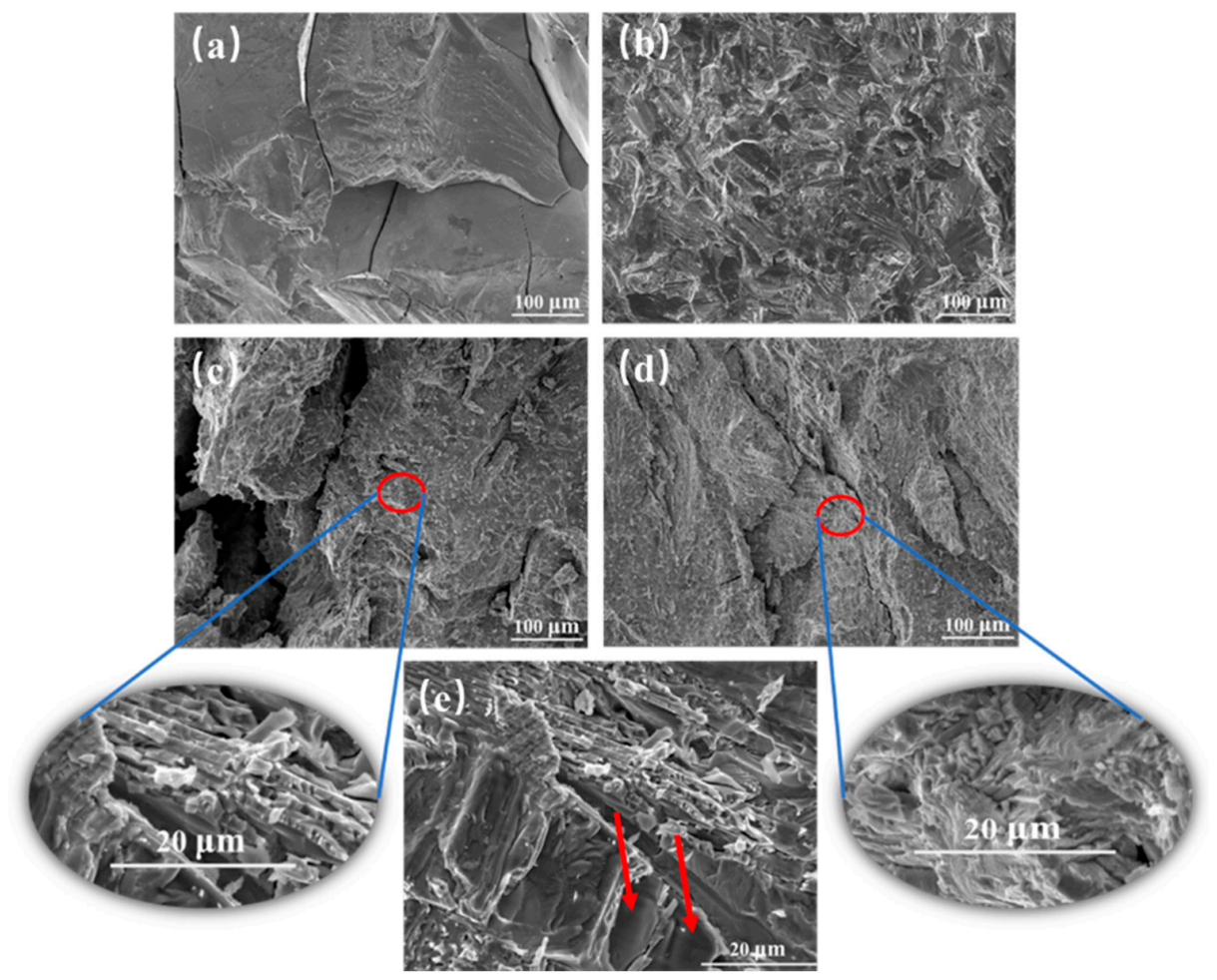

Figure 8. SEM fractographs of $\mathrm{Ni}_{48} \mathrm{Mn}_{39} \mathrm{Sn}_{13-x} \mathrm{~Tb}_{x}$ alloys (a) $x=0$; (b) $x=0.5$; (c) $x=1$; (d) $x=2$; (e) $x=5$.

\section{Conclusions}

In the present work, the martensitic transformation behaviors, microstructure, and mechanical properties of solution-treated $\mathrm{Ni}_{48} \mathrm{Mn}_{39} \mathrm{Sn}_{13-x} \mathrm{~Tb}_{x}(x=0,0.5,1,2$, and 5 at.\%) alloys were investigated. The obtained results are as follows:

1. The results show that $\mathrm{Tb}$ addition refines significantly the grains and causes the formation of a $\mathrm{Tb}$-rich phase. With the increase in $\mathrm{Tb}$ content, the $\mathrm{Tb}$-rich phase became larger and tended to distribute along the grain boundaries.

2. Martensitic transformation was observed in all $\mathrm{Ni}_{48} \mathrm{Mn}_{39} \mathrm{Sn}_{13-x} \mathrm{~Tb}_{x}(x=0,0.5,1,2$, and 5 at. $\%)$ alloys. The martensitic transformation temperatures increased remarkably with the increase in 
$\mathrm{Tb}$ content. The martensitic transformation start temperature $M_{\mathrm{S}}$ increased from $-60.7^{\circ} \mathrm{C}$ for $x=0$ to $364.1^{\circ} \mathrm{C}$ for $x=5$.

3. The appropriate amount ( 2 at. $\%$ ) of $\mathrm{Tb}$ addition in $\mathrm{Ni}_{48} \mathrm{Mn}_{39} \mathrm{Sn}_{13-} \mathrm{Tb}$ ( $(x=0,0.5,1,2$, and 5 at. $\%)$ alloys significantly enhanced the compressive strength and improved the ductility, which can be ascribed to the grain refinement. The compressive stress and strain increased, firstly with increasing $\mathrm{Tb}$ content up to 2 at.\%, and then decreased with the further increased Tb content. The compressive stress increased from 74.3 MPa to $571.8 \mathrm{MPa}$ and the compressive strain increased from $9.2 \%$ to $22.0 \%$ with increasing $\mathrm{Tb}$ content from 0 at. $\%$ to 2 at. $\%$.

4. When the content of $\mathrm{Tb}$ addition was less 2 at. $\%$, the fracture type changed from intergranular fracture to transgranular fracture with increasing $\mathrm{Tb}$ content, which was due to strengthening of the grain boundary with increasing $\mathrm{Tb}$ content. However, when the amount exceeded 2 at.\%, the large amount of Tb-rich phase, hard-brittle phase, had a negative effect on the mechanical properties.

Author Contributions: K.Z. conceived and designed the experiments; X.T., K.Z. and C.T. performed the experiments; C.T., E.G. analyzed the data; K.Z., C.T. and X.T. wrote the paper.

Acknowledgments: The authors acknowledge the support of National Natural Science Foundation of China (Grant Nos. 51471064 and 51301054); and Program for Youth Academic Backbone in Heilongjiang Provincial University (Grant No.1251G022); and Scientific Research Fund of Heilongjiang Provincial Education Department (No: 12541138).

Conflicts of Interest: The authors declare no conflicts of interest.

\section{References}

1. Ullakko, K.; Huang, J.K.; Kantner, C.; O’Handley, R.C.; Kokorin, V.V. Large Magnetic-Field-Induced Strain in $\mathrm{Ni}_{2}$ MnGa. Appl. Phys. Lett. 1996, 69, 1966-1968. [CrossRef]

2. Sutou, Y.; Imano, Y.; Koeda, N.; Omori, T.; Kainuma, R.; Ishida, K.; Oikawa, K. Magnetic and martensitic transformations of $\mathrm{NiMnX}(\mathrm{X}=\mathrm{In}, \mathrm{Sn}, \mathrm{Sb})$ ferromagnetic shape memory alloys. Appl. Phys. Lett. 2004, 85, 4358-4360. [CrossRef]

3. Murray, S.J.; Marioni, M.; Allen, S.M.; O'Handley, R.C.; Lograsso, T.A. 6\% magnetic-field-induced strain by twin-boundary motion in ferromagnetic Ni-Mn-Ga. Appl. Phys. Lett. 2000, 77, 886-888. [CrossRef]

4. Kainuma, R.; Imano, Y.; Ito, W.; Sutou, Y.; Morito, H.; Okamoto, S.; Kitakami, O.; Oikawa, K.; Fujita, A.; Kanomata, T.; et al. Magnetic-field-induced shape recovery by reverse phase transformation. Nature 2006, 439, 957-960. [CrossRef] [PubMed]

5. Sozinov, A.; Soroka, A.; Lanska, N.; Rameš, M.; Straka, L.; Ullakko, K. Temperature dependence of twinning and magnetic stresses in $\mathrm{Ni}_{46} \mathrm{Mn}_{24} \mathrm{Ga}_{22} \mathrm{Co}_{4} \mathrm{Cu}_{4}$ alloy with giant $12 \%$ magnetic field-induced strain. Scr. Mater. 2017, 131, 33-36. [CrossRef]

6. Sozinov, A.; Likhachev, A.A.; Lanska, N.; Ullakko, K. 10\% magnetic-field-induced strain in Ni-Mn-Ga seven-layered martensite. Appl. Phys. Lett. 2002, 80, 1746-1748. [CrossRef]

7. Karaca, H.E.; Karaman, I.; Basaran, B.; Chumlyakov, Y.J.; Maier, H.J. Magnetic field and stress induced martensite reorientation in NiMnGa ferromagnetic shape memory alloy single crystals. Acta Mater. 2006, 54, 233-245. [CrossRef]

8. Karaca, H.E.; Karaman, I.; Basaran, B.; Ren, Y.; Chumlyakov, Y.I.; Maier, H.J. Magnetic Field-Induced Phase Transformation in NiMnCoIn Magnetic Shape-Memory Alloys-A New Actuation Mechanism with Large Work Output. Adv. Funct. Mater. 2009, 19, 983-998. [CrossRef]

9. Soroka, A.; Sozinov, A.; Lanska, N.; Rameš, M.; Straka, L.; Ullakko, K. Composition and temperature dependence of twinning stress in non-modulated martensite of Ni-Mn-Ga-Co-Cu magnetic shape memory alloys. Scr. Mater. 2018, 144, 52-55. [CrossRef]

10. Bischoff, A.J.; Mayr, S.G. Acoustic emissions associated with stress-induced twin boundary mobility in $\mathrm{Fe}_{7} \mathrm{Pd}_{3}$ ferromagnetic shape memory alloys. Scr. Mater. 2017, 139, 162-165. [CrossRef]

11. Xuan, H.C.; Deng, Y.; Wang, D.H.; Zhang, C.L.; Han, Z.D.; Du, Y.W. Effect of annealing on the martensitic transformation and magnetoresistance in Ni-Mn-Sn ribbons. J. Phys. D Appl. Phys. 2008, 41, 215002. [CrossRef] 
12. Chatterjee, S.; Giri, S.; Majumdar, S.; De, S.K. Giant magnetoresistance and large inverse magnetocaloric effect in $\mathrm{Ni}_{2} \mathrm{Mn}_{1.36} \mathrm{Sn}_{0.64}$ alloy. J. Phys. D Appl. Phys. 2009, 42, 065001. [CrossRef]

13. Krenke, T.; Duman, E.; Acet, M.; Wassermann, E.F.; Moya, X.; Manosa, L.; Planes, A. Inverse magnetocaloric effect in ferromagnetic Ni-Mn-Sn magnetic alloys. Nat. Mater. 2005, 4, 450-454. [CrossRef] [PubMed]

14. Liu, J.; Gottschall, T.; Skokov, K.P.; Moore, J.D.; Gutfleisch, O. Giant magnetocaloric effect driven by structural transitions. Nat. Mater. 2012, 11, 620-626. [CrossRef] [PubMed]

15. Castillo-Villa, P.O.; Manosaet, L.; Planes, A.; Frontera, C. Elastocaloric and magnetocaloric effects in Ni-Mn-Sn (Cu) shape-memory alloy. Appl. Phys. 2013, 113, 053506. [CrossRef]

16. Pecharsky, V.K.; Gschneidner, K.A.G., Jr. Giant magnetocaloric effect in $\mathrm{Gd}_{5}\left(\mathrm{Si}_{2} \mathrm{Ge}_{2}\right)$. Phys. Rev. Lett. 1997, 78, 4494-4497. [CrossRef]

17. Tegus, O.; Brück, E.; Buschow, K.H.J.; Boer, F.R.D. Transition-metal-based magnetic refrigerants for room-temperature applications. Nature 2002, 415, 150-152. [CrossRef] [PubMed]

18. Franco, V.; Conde, A. Magnetic refrigerants with continuous phase transitions: Amorphous and nanostructured materials. Scr. Mater. 2012, 67, 594-599. [CrossRef]

19. Moya, X.; Kar-Narayan, S.; Mathur, N.D. Caloric materials near ferroic phase transitions. Nat. Mater. 2014, 13, 439-450. [CrossRef] [PubMed]

20. Sandeman, K.G. Magnetocaloric materials: The search for new systems. Scr. Mater. 2012, 67, 566-571. [CrossRef]

21. Caron, L.; Ou, Z.Q.; Nguyen, T.T.; Cam Thanh, D.T.; Tegus, O.; Brück, E. On the determination of the magnetic entropy change in materials with first-order transitions. J. Magn. Magn. Mater. 2009, 321, 3559-3566. [CrossRef]

22. Shen, B.G.; Sun, J.R.; Hu, F.X.; Zhang, H.W.; Cheng, Z.H. Recent progress in exploring magnetocaloric materials. Adv. Mater. 2009, 21, 4545-4564. [CrossRef]

23. Sun, W.; Liu, J.; Zhao, D.; Zhang, M. Directional solidification and elastocaloric effect in a $\mathrm{Ni}_{45} \mathrm{Mn}_{44} \mathrm{Sn}_{11}$ magnetic shape memory alloy. J. Phys. D Appl. Phys. 2017, 50, 444001. [CrossRef]

24. Cai, W.; Gao, L.; Liu, A.L.; Sui, J.H.; Gao, Z.Y. Martensitic transformation and mechanical properties of $\mathrm{Ni}-\mathrm{Mn}-\mathrm{Ga}-\mathrm{Y}$ ferromagnetic shape memory alloys. Scr. Mater. 2007, 57, 659-662. [CrossRef]

25. Singh, R.K.; Raja, M.M.; Mathur, R.P.; Shamsuddin, M. Studies on ferromagnetic shape memory Ni-Mn-Ga alloys with Fe and rare-earths additives. J. Alloys Compd. 2010, 506, 73-76. [CrossRef]

26. Zhang, X.; Sui, J.H.; Yu, Z.L.; Cai, W. Structure and shape memory effect in a $\mathrm{Ni}_{54} \mathrm{Mn}_{25} \mathrm{Ga}_{20} \mathrm{Gd}_{1}$ alloy with a high transformation temperature. J. Alloys Compd. 2011, 31, 8032-8037. [CrossRef]

27. Tsuchiya, K.; Tsutsumi, A.; Ohtsuka, H.; Umemoto, M. Modification of Ni-Mn-Ga ferromagnetic shape memory alloy by addition of rare earth elements. Mater. Sci. Eng. A 2004, 378, 370-376. [CrossRef]

28. Tan, C.L.; Zhang, K.; Tian, X.; Cai, W. Effect of Gd addition on microstructure, martensitic transformation and mechanical properties of $\mathrm{Ni}_{50} \mathrm{Mn}_{36} \mathrm{Sn}_{14}$, ferromagnetic shape memory alloy. J. Alloys Compd. 2016, 692, 288-293. [CrossRef]

29. Shen, Q.; Zhao, D.; Sun, W.; Li, Y.; Liu, J. The effect of Tb on elastocaloric and mechanical properties of Ni-Mn-In-Tb alloys. J. Alloys Compd. 2017, 696, 538-542. [CrossRef]

30. Yuce, S.; Barrio, M.; Emre, B.; Stern-Taulats, E.; Planes, A.; Tamarit, J.L.; Mudryk, Y.; Gschneidner, K.A., Jr.; Pecharsky, V.K.; Mañosa, L. Barocaloric effect in the magnetocaloric prototype $\mathrm{Gd}_{5} \mathrm{Si}_{2} \mathrm{Ge}_{2}$. Appl. Phys. Lett. 2012, 101, 071906. [CrossRef]

31. Wroblewski, R.; Leonowicz, M.; Zhao, Z.; Liping, J. Structure and properties of Ni-Mn-Ga magnetic shape memory alloys containing minor addition of terbium. J. Magn. Magn. Mater. 2007, 316, e595-e598. [CrossRef]

32. Planes, A.; Manosaet, L.; Acet, M. Magnetocaloric effect and its relation to shape-memory properties in ferromagnetic Heusler alloys. J. Phys. Condens. Matter 2009, 21, 1425-1438. [CrossRef] [PubMed]

33. Jiang, C.B.; Muhammad, Y.; Deng, L.F.; Wu, W.; Xu, H.B. Composition dependence on the martensitic structures of the Mn-rich NiMnGa alloys. Acta Mater. 2004, 52, 2779-2785. [CrossRef]

34. Zhang, X.; Sui, J.H.; Zheng, X.H.; Yang, Z.Y.; Cai, W. Effects of Gd doping on $\mathrm{Ni}_{54} \mathrm{Mn}_{25} \mathrm{Ga}_{21}$ high-temperature shape memory alloy. Mater. Sci. Eng. 2014, 597, 178-182. [CrossRef]

(C) 2018 by the authors. Licensee MDPI, Basel, Switzerland. This article is an open access article distributed under the terms and conditions of the Creative Commons Attribution (CC BY) license (http://creativecommons.org/licenses/by/4.0/). 